\title{
Determination of factors affecting expenditures on three major food groups in Al-Ain, the United Arab Emirates (UAE)
}

\author{
Mohamed S. Gheblawi and Sherin A. Sherif \\ Department of Agribusiness and Consumer Science, Faculty of Food and Agriculture, \\ UAE University, P.O. Box 17555 Al-Ain, UAE
}

\begin{abstract}
A cross-section random sample of 485 households residing in Al-Ain, UAE, comprised of 270 Emirati citizens, 116 Arabic-speaking residents, 43 English-speaking residents, and 56 Urdu-speaking residents, was elicited. The questionnaire directed to the heads of the households included two main sections on amounts consumed and expenditures made on each food item bought. The study utilized the procedure of estimating expenditure functions on three main food items/groups: rice, seafood, and meats. Some of the results indicated that (1) income and household size were always critical factors affecting the amount of money spent on the three examined food groups, and (2) the expenditure on the three examined food items/groups was not highly responsive to changes in households' incomes.
\end{abstract}

Key words: Determinants of food expenditure, income-expenditure elasticity.

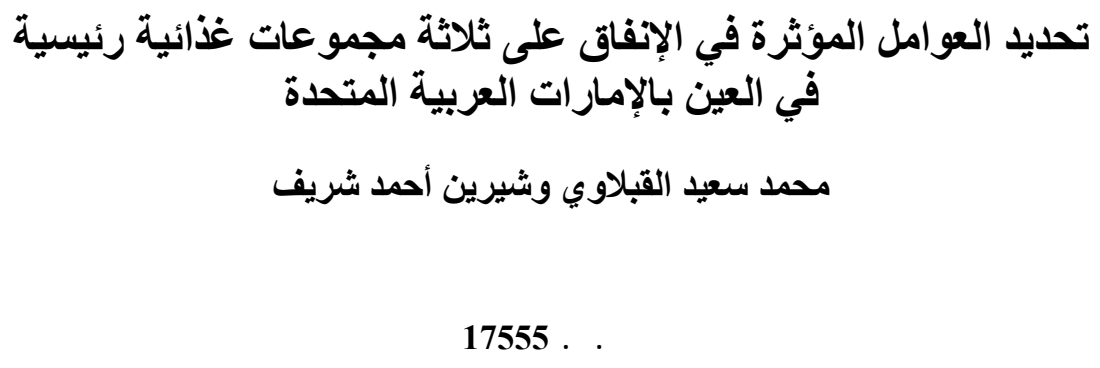

الملخص: م تجمبع بيانتا من أربلب 485 أسرة مكونة لعينة قاعية عثوائية من العين في الإمارات العربي ـة المتح ــة

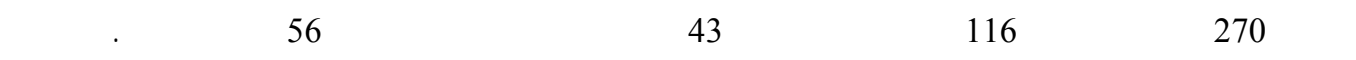

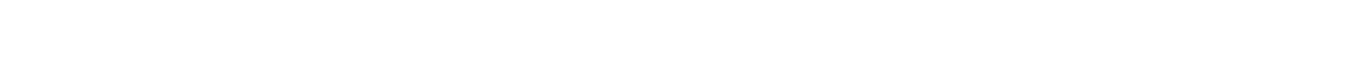

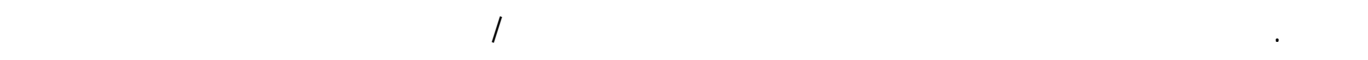

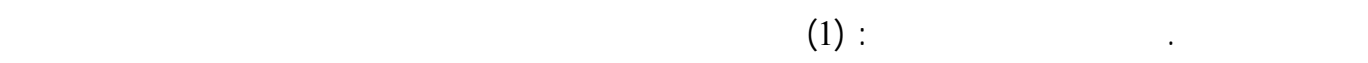

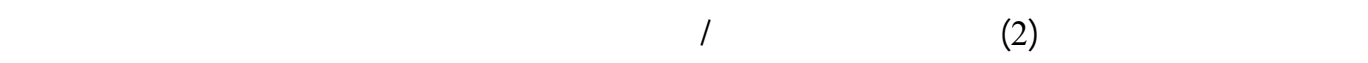
نخل الأسرة. الكامل الففتلحية: محددات الإفلق على الغذاء، مرونة النل الاففلقية.

\section{Introduction}

The standard of living in the UAE, as measured by the World Bank's per-capita national income, is among the highest in the Middle-East region and is estimated to be around $\$ 22,670$ per year (World Bank, 2000). Consequently, demand for most consumer commodities in general, and particularly those of foodstuff, may be affected by factors that are not considered important in some other countries in the region (El-Eraky et al., 2004). Taste, for instance, may be believed to be an important factor affecting the quantities demanded of some major foodstuff products since food safety and quality are anticipated to be major 
concerns on the consumers' demand agenda. The same could be said about the impact of other non-price factors on consumer behavior (Bashir, 2005).

This paper is intended to examine consumption expenditure determinants for three major food stuffs (rice; seafood and marine products; and meat and poultry) for the four main resident groups that compose the UAE population, and consequently Al-Ain (Ministry of Economy and Planning. Census 2005, UAE). These four resident groups are the Emirati citizens, the Arabic-speaking residents, the English-speaking residents, and the Urdu-speaking residents; it is intended to calculate income-expenditure elasticities for these four different ethnic groups for the three food items/groups chosen.

The remainder of the paper will first introduce the theoretical background for the research and list the empirical models. The next part will deal with the data and the methods of analysis. Then the results are listed and discussed. The final part of the paper discusses the conclusion and the recommendations.

\section{Theoretical Background and Empirical Models}

The expenditure function e $(p, u)$ estimated in this study for three major food groups: rice, seafood, and meats is defined in theory as the minimum income necessary for a consumer to achieve utility level $\mathrm{u}$ given a vector of prices for goods $\mathrm{p}$, assuming that the consumer is to obtain utility/satisfaction from the consumption of these goods (Deaton et al., 1980). It is an alternative way of examining consumers' behavior when demand functions are hard to obtain, as in the case of this study, since price variations for the different goods consumed did not yield significant impacts on the quantities consumed (Clements, 1987). This is due to data being extracted in a short period of time (six months; from fall 2005 to winter 2006) which did not allow for significant price variations to be reflected on the quantities demanded. In this case, the amount spent on a certain food item is a function of the variables affecting it such as age, educational level, income, household size, and the like (Deaton, 1986).

A great number of studies have dealt with estimating consumer demand, particularly on foodstuffs. Examples include the work done by Deaton (1986) on demand analysis; Deaton and Muellbauer (1980) on the economics of consumer behavior, and Clements (1987) on alternative approaches to consumption theory. Moreover, the works of Sapsford and Morgan (1994), and Meyer and Johnson (1995), on empirical demand studies are of importance in this context. Other prominent authors cited in consumer theory include Blundell (1988) on "Consumer behavior: theory and empirical evidence," and Theil (1975) on theory and measurement of consumer demand.

Barnes and Gillingham (1984) used the quadratic expenditure system while incorporating demographic variables and found that unrestricted estimation yields significant explanatory power. Their estimates of the food at home expenditure elasticities ranged from 0.686 to 1.155 . Barnes and Gillingham used four goods: food at home, food away from home, shelter and clothing. The results provided insight into the complexity of the way in which a household's demand behavior is conditional on its demographic profile. This study elaborates on this topic and investigates the role of demographics in explaining consumer decisions in consuming three major food items.

Behrman and Deolalikar's (1987) results indicated that aggregation of food items and nutrients results in over estimation of food expenditure elasticities. They pointed out that maybe such an overestimation is acceptable by economists due to the fact that detailed disaggregating 
of food lists results in major difficulties of estimating large expenditure systems.

Subramanian and Deaton (1996) reported estimated elasticity of calorie consumption with respect to total expenditure in the range of 0.3 to 0.5 . They used a double logarithmic linear model and fitted it by utilizing ordinary least squares. The dependent variable was calories and the explanatory variables included a set of demographic attributes including religious persuasion. The present study utilizes a similar model in addition to the inclusion of ethnicity of customers and its effect on consumption of major food items in Al-Ain.

In this study, the general model utilized for the estimation of the expenditure functions for the three food commodities/groups previously specified is of the following linear type:

$\ln \mathrm{EXP}_{\mathrm{i}}=\beta_{0}+\beta_{1} \mathrm{ARAB}+\beta_{2} \mathrm{ENGL}+\beta_{3}$ $\mathrm{URDU}+\beta_{4} \ln \mathrm{INC}+\beta_{5} \mathrm{AGE}+\beta_{6}$ INDS $+\beta_{7} \mathrm{EDU}+\mathrm{e}$

Where $\ln$ stands for the natural logarithm, EXP for expenditure, $i$ is the food item/group in question (rice, seafood, and meats), $\beta_{0}$ is the intercept, and $\beta_{1}, \beta_{2}$, and $\beta_{3}$ are binary (dummy) variables that take the values of 0 or 1 . For Emirati citizens, the three $\beta$ 's are zero; for Arabic-speaking residents (ARAB), $\beta_{1}=1$ while $\beta_{2}$ and $\beta_{3}$ are zeros; For English-speaking residents (ENGL), $\beta_{2}=1$ while $\beta_{1}$ and $\beta_{3}$ are zeros; for Urdu-speaking residents (URDU), $\beta_{3}$ $=1$ while $\beta_{1}$ and $\beta_{2}$ are zeros (Wooldridge, 2003); INC stands for monthly income measured in Dirhams in a logarithmic form; AGE stands for age measured in years; INDS stands for the number of individual family members supported by the head of the household interviewed; EDU for educational level of the head of the household which takes the values $6,5,4,3,2,1$, and 0 for postgraduate education, university graduate, diploma holder, high school graduate, preparatory school graduate, primary school graduate, and illiterate respectively; while e is the equation's error term.

The empirical models utilized in this study are as follows:

Model 1: Rice expenditure function for the whole sample

$\ln \mathrm{EXP}_{\text {Rice }}=\beta_{0}+\beta_{1}$ ARAB $+\beta_{2}$ ENGL + $\beta_{3} \mathrm{URDU}+\beta_{4} \ln \mathrm{INC}+\beta_{5} \mathrm{AGE}+\beta_{6}$ $\mathrm{INDS}+\beta_{7} \mathrm{EDU}+\mathrm{e}$

Model 2: Rice expenditure function for Emirati citizens

$\ln \mathrm{EXP}_{\text {Rice }}=\beta_{0}+\beta_{1} \ln \mathrm{INC}+\beta_{2} \mathrm{AGE}+\beta_{3}$ INDS $+\beta_{4} \mathrm{EDU}+\mathrm{e}$

Model 3: Rice expenditure function for the whole sample with monthly income range AED 2000 to AED 20,000 1

$\ln \mathrm{EXP}_{\text {Rice }}=\beta_{0}+\beta_{1} \mathrm{ARAB}+\beta_{2} \mathrm{ENGL}+$ $\beta_{3} \mathrm{URDU}+\beta_{4} \ln \mathrm{INC}+\beta_{5} \mathrm{AGE}+\beta_{6}$ $\mathrm{INDS}+\beta_{7} \mathrm{EDU}+\mathrm{e}$

Model 4: Seafood expenditure function for the whole sample

$\ln \mathrm{EXP}_{\text {Seafood }}=\beta_{0}+\beta_{1} \mathrm{ARAB}+\beta_{2} \mathrm{ENGL}+$ $\beta_{3} \mathrm{URDU}+\beta_{4} \ln \mathrm{INC}+\beta_{5}$ AGE $+\beta_{6}$ $\mathrm{INDS}+\beta_{7} \mathrm{EDU}+\mathrm{e}$

Model 5: Seafood expenditure function for Emirati citizens

$\ln \mathrm{EXP}_{\text {Seafood }}=\beta_{0}+\beta_{1} \ln \mathrm{INC}+\beta_{2} \mathrm{AGE}+$ $\beta_{3}$ INDS $+\beta_{4}$ EDU $+\mathrm{e}$

Model 6: Seafood expenditure function for the whole sample with monthly income range AED 2000 to AED 20,000

$\ln \mathrm{EXP}_{\text {Seafood }}=\beta_{0}+\beta_{1} \mathrm{ARAB}+\beta_{2} \mathrm{ENGL}+$ $\beta_{3} \mathrm{URDU}+\beta_{4} \ln \mathrm{INC}+\beta_{5} \mathrm{AGE}+\beta_{6}$ $\mathrm{INDS}+\beta_{7} \mathrm{EDU}+\mathrm{e}$

Model 7: Meats expenditure function for the whole sample

$\ln \mathrm{EXP}_{\text {Meats }}=\beta_{0}+\beta_{1} \mathrm{ARAB}+\beta_{2} \mathrm{ENGL}+$ $\beta_{3}$ URDU $+\beta_{4} \ln$ INC $+\beta_{5}$ AGE $+\beta_{6}$ INDS $+\beta_{7}$ EDU $+\mathrm{e}$

\footnotetext{
${ }^{1}$ One US Dollar is equivalent to 3.675 AED (United Arab Emirates Dirham).
} 
Model 8: Meats expenditure function for Emirati citizens

$\ln \mathrm{EXP}_{\text {Meats }}=\beta_{0}+\beta_{1} \ln \mathrm{INC}+\beta_{2} \mathrm{AGE}+$ $\beta_{3}$ INDS $+\beta_{4}$ EDU $+\mathrm{e}$

Model 9: Meats expenditure function for the whole sample with monthly income range AED 2000 to AED 20,000

$\ln \mathrm{EXP}_{\text {Meats }}=\beta_{0}+\beta_{1} \mathrm{ARAB}+\beta_{2} \mathrm{ENGL}$ $+\beta_{3} \mathrm{URDU}+\beta_{4} \ln \mathrm{INC}+\beta_{5} \mathrm{AGE}+\beta_{6}$ $\mathrm{INDS}+\beta_{7} \mathrm{EDU}+\mathrm{e}$

Models 3, 6, and 9 are restricted to monthly income range AED 2,000- AED 20,000 since most of the sample reported incomes within this range and incomes outside the range are eliminated in order to reduce their outlying effect on the estimates.

\section{Data and Methods}

A major comprehensive field survey directed to the four different ethnic groups who make up the Al-Ain population was conducted. The sample was composed of 270 Emirati citizens, 116 Arabic-speaking residents, 43 English-speaking residents, and 56 Urduspeaking residents. This made a total sample interviewed of 485 household heads. The planned interviewees were supposed to be a total of 550 household heads (a success ratio of $88 \%$ ). Al-Ain's total population is a little less than half a million and therefore, the sample is considered representative of the population. Direct interviews with the household heads who shop from the different major food-shopping outlets in Al-Ain were made. Data collection started in September $1^{\text {st }}, 2005$ and ended in the winter of 2006.

The three sections of the administered questionnaire pertinent to this study were (1) General information about the interviewed household, (2) Data pertinent to shopping habits for foodstuffs, and (3) Questions related to the amounts consumed of the different foodstuffs (type of food and quantities consumed per visit to the market). Three languages for the questionnaire were offered to households: Arabic, English, and Urdu. Although the direct personal interviews method was utilized for the Emirati citizens, Arabic-speaking residents, and English-speaking residents, this was not the case for the Urdu-speaking residents ${ }^{2}$. Linear multiple regression analysis was the quantitative statistical technique used through the ordinary least squares (OLS) criterion $^{3}$.

\section{Results and Discussion}

Three main food items or groups were analyzed in order to extract their corresponding expenditure functions, to identify the factors affecting the amount spent by the households on each food item or group, and to estimate the incomeexpenditure elasticity. The three food items/groups examined were Rice (as the major staple food item), Seafood, and Meats.

Out of 485 household heads interviewed, a total of 360 households were found to spend money on buying rice. Out of these 360 households, 197 were Emirati citizens, 94 Arabic-speaking residents, 20 English-speaking residents, and 49 Urdu-speaking residents. Table 1 shows the mean and standard deviation values for the variables: monthly expenditure on rice in Dirhams (EXP), age in years (AGE), monthly income in Dirhams (INC), education (EDU), and numbers of family members (INDS). Great variations and dispersions, as expressed by values of the different standard deviations, were found. One of the reasons for this great dispersion is the fact that the sample included the four different ethnic groups.

\footnotetext{
${ }^{2}$ Instead, questionnaires written in Urdu were handed out to the respondents for them to fill out.

${ }^{3}$ The statistical software used was SPSS, version 15.
} 
The sample also showed that 411 households out of a total of 485 households consumed seafood and marine products monthly. Out of these 411 households, 233 were Emirati citizens, 111 were Arabic-speaking residents, 29 were English-speaking residents, and 38 were of the Urduspeaking residents. Furthermore, 435 households were found to spend money on meats, out of which, 249 were Emirati citizens, 111 were Arabic-speaking residents, 28 English-speaking residents, and 47 Urdu-speaking residents.

Table 1. Descriptive statistics of the three sub-samples.

\begin{tabular}{ccccccc}
\hline \multirow{2}{*}{ Variable } & \multicolumn{2}{c}{ Rice $(\mathrm{n}=360)$} & \multicolumn{2}{c}{ Seafood $(\mathrm{n}=411)$} & \multicolumn{2}{c}{ Meats $(\mathrm{n}=435)$} \\
\cline { 2 - 7 } & Mean & Std. Dev. & Mean & Std. Dev. & Mean & Std. Dev. \\
\hline EXP & 129.391 & 142.0338 & 259.973 & 205.6172 & 457.15 & 425.051 \\
AGE & 36.92 & 10.342 & 36.70 & 10.242 & 36.48 & 10.081 \\
INC & 7809.51 & 6340.140 & 8141.03 & 6238.405 & 7964.21 & 6030.021 \\
EDU & 4.39 & 1.273 & 4.54 & 1.162 & 4.48 & 1.243 \\
INDS & 6.63 & 4.400 & 6.29 & 4.350 & 6.45 & 4.444
\end{tabular}

Source: Calculated from the cross section data analysis of the study.

Table 2 displays the descriptive statistics only of the Emirati citizens who consumed the three previously mentioned food groups. One hundred and ninety seven, two hundred and thirty three, and two hundred and forty nine households were found to consume rice, seafood, and meats respectively. High dispersions were found in almost all of the designated variables, particularly those of expenditures (EXP), incomes (INC), and household size (INDS).

Table 2. Descriptive statistics of the Emirati citizens sub-samples.

\begin{tabular}{ccccccc}
\hline \multirow{2}{*}{ Variable } & \multicolumn{2}{c}{ Rice $(\mathrm{n}=197)$} & \multicolumn{2}{c}{ Seafood $(\mathrm{n}=233)$} & \multicolumn{2}{c}{ Meats $(\mathrm{n}=249)$} \\
\cline { 2 - 7 } & Mean & Std. Dev. & Mean & Std. Dev. & Mean & Std. Dev. \\
\hline EXP & 171.224 & 171.0402 & 297.326 & 235.2750 & 620.73 & 489.103 \\
AGE & 34.85 & 10.786 & 34.37 & 10.286 & 34.43 & 10.273 \\
INC & 10498.86 & 7085.182 & 10447.96 & 7025.345 & 10261.63 & 6691.792 \\
EDU & 4.36 & 1.284 & 4.48 & 1.178 & 4.43 & 1.246 \\
INDS & 7.75 & 5.019 & 7.37 & 4.896 & 7.55 & 5.028 \\
\hline
\end{tabular}

Source: Calculated from the cross section data analysis of the study.

The estimated linear expenditure function, with both the dependent variable rice expenditure and income taken in natural logarithmic form, showed that the independent variables for the whole sample that consumed rice with all ethnic groups included were responsible for $42.6 \%$ of the variations in rice expenditure.

The model showed that the most prominent variables affecting rice expenditure for the whole sample were number in household, income, and age respectively ${ }^{4}$. English-speaking residents were found to spend $48.8 \%$ less on rice per month than Emirati citizens on average. Nothing could be said about the behavior of Arabic-speaking residents and Urdu-

\footnotetext{
${ }^{4}$ The standardized coefficient (Beta) is calculated through multiplying the estimated regression coefficient of the independent variable by the ratio of the standard deviation of the independent variable and that of the dependent variable. According to this standardized coefficient, the higher the Beta value, the more important the independent variable is in affecting the dependent variable regardless of its algebraic sign.
} 
speaking residents due to the insignificance of their corresponding coefficients. On the other hand, the income elasticity of rice expenditure was estimated at 0.282 , which means that if income rises by $10 \%$, rice expenditure will rise by $2.82 \%$. This means that rice expenditure is income inelastic. This is normal since that rice is a staple food.

Repeating the same function for Emirati citizens only revealed no considerable changes from the previous whole model with the same incomeexpenditure elasticity value of 0.282 . This is probably because the Emirati citizens who consumed rice accounted for $54.7 \%$ of the whole rice-consuming sample.

Furthermore, repeating the above function after sorting out the whole sample according to income, and utilizing only the sample which had greater than or equal to AED 2000/mo. and less than or equal to AED $20,000 /$ mo., i.e., excluding the extreme income figures from below and from above, resulted in an income-expenditure elasticity of 0.242 (if income is to rise by $10 \%$, rice expenditure is to rise by $2.42 \%$ ), and English-speaking residents rice expenditure was less than that of Emirati citizens by $50.5 \%$ per month. Contrasting that with the whole sample rice model yielded no significant variations from that of the whole model, other than having a little lower incomeexpenditure elasticity, and that the variable "age" came one step up to second place in terms of its importance on rice expenditure, leaving "income" in third place.

The most prominent variables having impacts on seafood and marine products expenditure were number of household family members, income, educational level, and age respectively. Incomeexpenditure elasticity was estimated at 0.239 for the whole sample. This means that it is also inelastic to income; i.e., if income is to rise by $10 \%$, expenditure on seafood and marine products will rise by $2.39 \%$. This could be due to the fact that people in the UAE and Gulf states, in general, are way more than world average seafood consumers, combined with the fact that there are different types of seafood in the markets that greatly vary in price.

The same function was repeated for only the Emirati citizens since the sample showed that $56.7 \%$ of seafood consumers were Emiratis. The most prominent variables affecting seafood expenditure were size of household and income respectively. The significance of income, however, was not as high as that when the whole sample was included. Income elasticity of expenditure was estimated at 0.180 , i.e. inelastic, and meaning that when income rises by $10 \%$, expenditure on seafood and marine products will rise by $1.8 \%$.

Repeating the same function for the whole sample for monthly income groups greater than or equal to AED 2000/mo and less than or equal to AED 20,000/mo yielded similar results to the riceexpenditure case with income-expenditure elasticity slightly less than that for the whole model (0.206 instead of 0.239 ), and only the education and income variables were found to be statistically significant.

The model showed that the elasticity of income expenditure of meats was set at 0.697 (inelastic) for the whole sample (but higher than those of rice and/or seafood). This means that an increase in income by $10 \%$ results in increasing expenditure on meats by $6.97 \%$. The model also showed that expenditure on meats by the Englishspeaking residents per month was less than that of Emirati citizens by $49.8 \%$. Although expenditure on meat for Arabspeaking residents and Urdu-speaking residents, like the previous two cases for rice and seafood, was less than that for Emirati citizens, the statistical significance was not conclusive. The most important factors affecting meat and poultry expenditure were income, household size, and age respectively. 
Repeating the above analysis for only the Emirati citizens showed that 57.2\% of the sample that consumed meats were Emirati citizens. The most prominent factors affecting the expenditure on this food group were household size, income, and age respectively. Incomeexpenditure elasticity for this food group was estimated at 0.79 , still inelastic, but this inelasticity was found to be higher than that of the whole sample. This means that an increase in income of $10 \%$ results in increasing expenditure on meats by $7.9 \%$ for Emirati citizens. Moreover, repeating the whole model after including only the monthly income brackets greater than or equal to AED 2000/mo and less than or equal to AED 20,000/mo resulted in having a little higher income-expenditure elasticity $(0.716$ instead of 0.697) and a change in the ordering of importance of the variables affecting meats expenditure (family size followed by income and age). No other significant differences were found between the two models contrasted.

Table 3. Results of the expenditure functions' models.

\begin{tabular}{|c|c|c|c|c|c|c|c|c|c|}
\hline Variable & Model 1 & Model 2 & Model 3 & Model 4 & Model 5 & Model 6 & Model 7 & Model 8 & Model 9 \\
\hline Intercept & $\begin{array}{l}.647 \\
(.860)\end{array}$ & $\begin{array}{c}.711 \\
(1.238)\end{array}$ & $\begin{array}{c}.846 \\
(1.122)\end{array}$ & $\begin{array}{l}2.317^{*} \\
(.768)\end{array}$ & $\begin{array}{c}3.015^{*} \\
.993\end{array}$ & $\begin{array}{l}2.709^{*} \\
(1.000)\end{array}$ & $\begin{array}{l}-.911^{*} \\
(.486)\end{array}$ & $\begin{array}{c}-1.620^{*} \\
(.624)\end{array}$ & $\begin{array}{c}-1.142 * \\
(.614)\end{array}$ \\
\hline ARAB & $\begin{array}{l}-.049 \\
(.131)\end{array}$ & & $\begin{array}{l}-.082 \\
(.137)\end{array}$ & $\begin{array}{l}-.023 \\
(.113)\end{array}$ & & $\begin{array}{l}-.009 \\
(.120)\end{array}$ & $\begin{array}{l}-.059 \\
(.070)\end{array}$ & & $\begin{array}{l}-.051 \\
(.073)\end{array}$ \\
\hline ENGL & $\begin{array}{l}-.488^{*} \\
(.204)\end{array}$ & & $\begin{array}{l}-.505^{*} \\
(.204)\end{array}$ & $\begin{array}{l}-.109 \\
(.160)\end{array}$ & & $\begin{array}{l}-.058 \\
(.161)\end{array}$ & $\begin{array}{l}-.498^{*} \\
(.100)\end{array}$ & & $\begin{array}{l}-.499 * \\
(.099)\end{array}$ \\
\hline URDU & $\begin{array}{c}.014 \\
(.204)\end{array}$ & & $\begin{array}{c}.027 \\
(.235)\end{array}$ & $\begin{array}{l}-.112 \\
(.191)\end{array}$ & & $\begin{array}{l}-.067 \\
(.224)\end{array}$ & $\begin{array}{l}-.110 \\
(.115)\end{array}$ & & $\begin{array}{l}-.099 \\
(.131)\end{array}$ \\
\hline AGE & $\begin{array}{l}.012^{*} \\
(.005)\end{array}$ & $\begin{array}{l}.012^{*} \\
(.007)\end{array}$ & $\begin{array}{l}.013^{*} \\
(.005)\end{array}$ & $\begin{array}{l}.007 * \\
(.004)\end{array}$ & $\begin{array}{c}.008 \\
(.006)\end{array}$ & $\begin{array}{l}.006 \\
(.004)\end{array}$ & $\begin{array}{l}.006^{*} \\
(.003)\end{array}$ & $\begin{array}{l}.008^{*} \\
(.003)\end{array}$ & $\begin{array}{l}.007^{*} \\
(.003)\end{array}$ \\
\hline EDU & $\begin{array}{l}.028 \\
(.041)\end{array}$ & $\begin{array}{c}.014 \\
(.055)\end{array}$ & $\begin{array}{c}.045 \\
(.043)\end{array}$ & $\begin{array}{l}.071^{*} \\
(.038)\end{array}$ & $\begin{array}{l}.022 \\
(.047)\end{array}$ & $\begin{array}{l}.050 \\
(.040)\end{array}$ & $\begin{array}{l}-.013 \\
(.022)\end{array}$ & $\begin{array}{l}-.044^{*} \\
(.026)\end{array}$ & $\begin{array}{l}-.009 \\
(.022)\end{array}$ \\
\hline INDS & $\begin{array}{l}.115^{*} \\
(.011)\end{array}$ & $\begin{array}{l}.112^{*} \\
(.013)\end{array}$ & $\begin{array}{l}.121^{*} \\
(.011)\end{array}$ & $\begin{array}{l}.049^{*} \\
(.009)\end{array}$ & $\begin{array}{l}.053^{*} \\
(.011)\end{array}$ & $\begin{array}{l}.053^{*} \\
(.010)\end{array}$ & $\begin{array}{l}.076^{*} \\
(.006)\end{array}$ & $\begin{array}{l}.068^{*} \\
(.006)\end{array}$ & $\begin{array}{l}.078^{*} \\
(.006)\end{array}$ \\
\hline $\ln \mathrm{INC}$ & $\begin{array}{l}.282^{*} \\
(.104)\end{array}$ & $\begin{array}{l}.282^{*} \\
(.142)\end{array}$ & $\begin{array}{l}.242^{*} \\
(.133)\end{array}$ & $\begin{array}{l}.239^{*} \\
(.093)\end{array}$ & $\begin{array}{l}.180 \\
(.114)\end{array}$ & $\begin{array}{l}.206^{*} \\
(.117)\end{array}$ & $\begin{array}{l}.697^{*} \\
(.058)\end{array}$ & $\begin{array}{l}.790^{*} \\
(.072)\end{array}$ & $\begin{array}{l}.716^{*} \\
(.072)\end{array}$ \\
\hline$R^{2}$ & .426 & .404 & .430 & .183 & .175 & .134 & .703 & .634 & .643 \\
\hline$F$-statistic & 37.343 & 32.479 & 33.502 & 12.895 & 12.090 & 8.204 & 144.044 & 105.626 & 100.187 \\
\hline
\end{tabular}

Source: Calculated from the cross section data analysis of the study. Standard errors are between parentheses Coefficient is significant at $\alpha=0.10$

\section{Conclusions and Recommendations}

With respect to monthly expenditure on the three food items or groups examined: rice, seafood, and meats, income was found to be inelastic to monthly expenditure when either the whole sample was examined, or when Emirati citizens only were included in the analysis in varying degrees of inelasticity. This means that should income increase by a certain percentage, expenditure on any of the examined three food items or groups would increase, but by a lesser percentage. Moreover, excluding extreme income groups from below (less than AED 2000/mo) and from above (more than AED 20,000/mo) resulted in slight alteration in the value of income elasticity (a little less in the case of rice and seafood and marine products, and a little more in the case of meat and poultry). In addition, homogenizing the income variable slightly altered the 
ordering of importance of the explanatory variables on expenditure for the above three food groups. The results of this study were comparable to the similar findings from other studies from different parts of the world. Subramanian and Deaton (1996) reported such findings and argued that these elasticities should not be considered as zero as the conventional wisdom dictates or equals to one as some late literature has been arguing for. The estimates obtained in this study confirmed the theory set forth by Subramanian and Deaton (1996), although the income effect may be different in both cases since their study was from a sample in rural India where average income is much less than the average income of the sample surveyed in this study.

If the Emirati government is to promote the income of seafood producers and/or meat producers (particularly the first), increasing consumers' incomes may not be the best instrument. This is because the inelastic income-expenditure coefficient for these two food groups, and particularly the first, means that increases in incomes result in less than comparable increases in expenditures on these food groups. However, information about the supply of these goods is required in order to reach a concrete policy recommendation. The case is also true for rice, but rice is not produced locally and is completely imported, in addition to being a staple food item for the Emirati families.

\section{Acknowledgement}

Financial support for this study was provided by The Research Affairs Sector of the United Arab Emirates University through grant \# 01-03-6-11/05.

\section{References}

Barnes, R. and R. Gillingham. 1984. Demographic Effects in Demand
Analysis: Estimation of the Quadratic Expenditure System Using Microdata. The Review of Economics and Statistics. 66( 4):591-601.

Bashir, K. 2005. Consumption of Dairy Products in the UAE: A Consumer Profile, The Sixth Annual UAE University Research Conference, AlAin, UAE.

Behrman, J. R. and A. B. Deolalikar. 1987. Will Developing Country Nutrition Improve with Income? A Case Study for Rural South India. The Journal of Political Economy. 95(3):492-507.

Blundell, R. 1988. Consumer Behavior: Theory and Empirical Evidence-A Survey, Economic Journal. pp.16-65.

Clements, K. W. 1987. Alternative Approaches to Consumption Theory. In: H. Theil and K. W. Clements (Eds.). Applied Demand Analysis. Pensacola. Ballinger Publishing.

Deaton, A. 1986. Demand Analysis. In: Z. Griliches and M. D. Intriligator (Eds.). Handbook of Econometrics, Volume 3, Amsterdam, The Netherlands. Elsevier Science Publishers.

Deaton, A. and J. Muellbauer. 1980. Economics and Consumer Behavior; New York, NY. Cambridge University Press, (chapters 1 and 2).

El-Eraky, M. and T. Al-Muhairi. 2004. Consumer Demand for Food in the United Arab Emirates: A Pilot Study", Proceedings of the Fifth Annual UAE University Research Conference, Volume 2, Al-Ain.

Meyer, R. and E. J. Johnson. 1995. Empirical Generalizations in the Modeling of Consumer Choice. Marketing Science, 14(3):2 of 2: 
Emir. J. Food Agric. 2007. 19 (2): 15-23

http://www.cfa.uaeu.ac.ae/research/ejfa.htm

Special Issue on Empirical Generalizations in Marketing (1995), pp.180-189

Ministry of Economy and Planning. Census 2005, UAE. Al Manara Jewelry Building, Hamdan Street, Abu Dhabi, UAE. Visited November 5, 2007 (http://tedad.ae/english/population_resu lts.html-

Sapsford, D. and W. Morgan. 1994. The Economics of Primary Commodities: Models, Analysis, and Policy. Glos. Edward Elgar.

Subramanian, S. and A. Deaton. 1996. The Demand for Food and Calories.
The Journal of Political Economy, 104(1):133-162.

The World Bank, Visited April 15, 2006.www.WorldBank.org./data/datab ytopic/qdp.html

Theil, H. 1975. Theory and Measurement of Consumer Demand, part I. Amsterdam, North-Holland.

Wooldridge, J. M. 2003. Introductory Econometrics: A Modern Approach, 2nd Edition, Thompson-South Western, Chapter 7, pp.218-256. 